\title{
Performance analysis of a microcontroller based slip power recovery drive
}

\author{
Ajay Kumar ${ }^{1}$, S. K. Aggarwal' ${ }^{2}$ L.M. Saini ${ }^{3}$, and Ashwani Kumar ${ }^{3, *}$ \\ ${ }^{l}$ EED, Baddi University of Emerging Sciences \& Technology, Baddi, Distt. Solan, HP 173205, INDIA \\ ${ }^{2}$ EED, M.M. Engineering College, Mullana, Ambala, 133203, INDIA \\ ${ }^{3,4}$ EED, National Institute of Technology, Kurukshetra, INDIA \\ *Corresponding Author: ashwa_ks@yahoo.com
}

\begin{abstract}
Slip power recovery wound rotor induction motor drives are used in high power, limited speed range applications where control of slip power provides the variable speed drive system. In this paper, the steady state performance analysis of conventional slip power recovery scheme using static line commutated inverter in the rotor circuit is presented. Simulation of the scheme is carried out using Matlab/Simulink environment and experimental set-up is prepared in the laboratory for a 2-hp wound rotor induction motor. Microcontroller technique is used for the generation of firing pulses for the inverter bridge. The simulation and experimental results are analyzed.
\end{abstract}

Keywords: Slip power recovery drive; simulation; experiment; speed control

\section{Introduction}

Induction motor drives with control of speed have huge applications in the modern industrial set up. More than $75 \%$ of the load today in the industry of any country consists of induction motor drives. Wound rotor induction motor drives have found great applications due to the availability of slip power easily available from slip rings and can be utilized mechanically or electronically for better speed control. Slip power can be recovered from static converters instead of wasting power in the resistance. High performance induction motor drive application requires low cost, high efficiency and simple control circuitry for the complete speed range. Nowadays, slip power recovery drives (SPRD), also known as Static Scherbius system, is widely used for the limited speed range applications such as large-capacity pumps and fan drives, variable-speed wind energy systems, ship-board variable speed/constant frequency system etc (Leonharn, 1985, Krishnan, 2001, Steibler, 2010). A schematic diagram of a SPRD is shown in Figure 1. It consists of a wound-rotor induction motor, a diode bridge rectifier, a large filter inductor, a line commutated inverter and a three-phase recovery transformer. A SPRD transfers power that is normally wasted in the rotor of an induction machine back to the ac mains supply to improve overall drive efficiency. In contrast with the stator-voltage-controlled induction motors, the ratings of the rotor side converter, inverter and transformer circuit in SPRD is designed to be smaller, lighter and less expensive as these components have to deal with the slip power only. Huge literature is available for slip power recovery drives. Many Authors (Zahawi et al, 1987, Brown et al. 1986, Doradla et al. 1998) presented motor performance using slip recovery systems, analysis of transient state of Kramer drives, and proposed new slip recovery scheme for improved power factor. Krause et al. 1988 presented reference analysis of slip power recovery drive. Akpinar and Pillai, 1990 proposed modeling and performance of slip power recovery scheme for induction motor. A new energy recovery scheme for variable speed double fed induction motor was proposed in (Fan et al., 1990). Many authors proposed commutation angle analysis, harmonic analysis and performance improvement of slip power energy recovery drive (Papathanassiou et al. 1998, Refoufi et al. 1996, Faiz et al, 2001).

The main purpose of this work is to analyze the performance of SPRD in laboratory environment using microcontroller as firing angle controller for the inverter circuit. The advantage of using microcontroller over digital and microprocessor techniques are it is simple, flexible, economical, and consumes less hardware. In this work, steady state relationships between torque, speed, inverter firing angle and inductor current for the SPRD are derived. By using dynamic model library in Matlab/Simulink, a simulation model of the drive is implemented. The simulated results are compared with an experimental set-up developed in the laboratory. It has been observed that the drive has a linear torque-current relationship like a separately excited DC motor. 


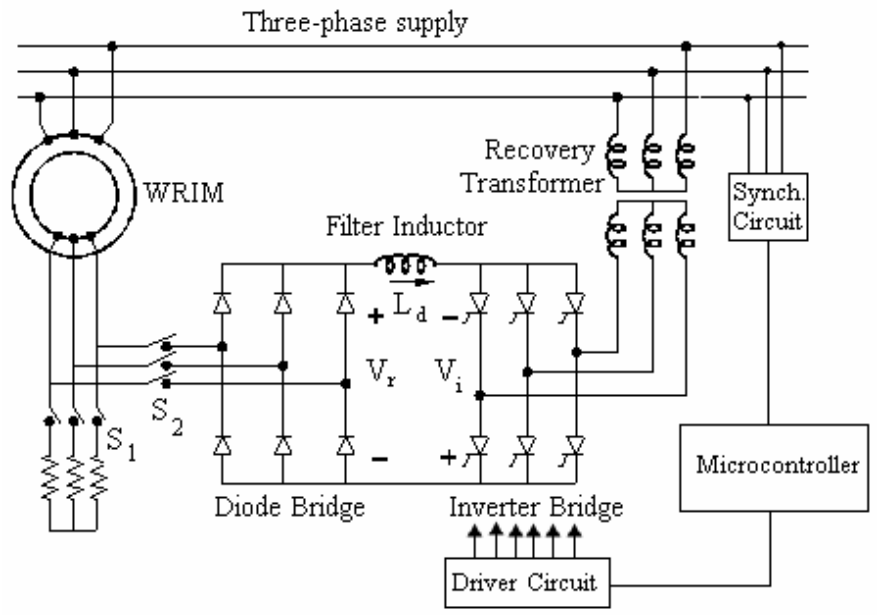

Figure 1. Schematic of Slip Power Recovery Drive (SPRD)

\section{Performance Analysis of the Drive}

Assuming negligible rotor leakage reactance and ideal filtering $\left(L_{d}=\infty\right)$, the rotor currents are alternating square pulses of $2 \pi / 3$ radians duration. The rms value of the total rotor current $I_{2}$ is $\pi / 3$ times the rms value of the fundamental component $I_{2 f}$ (Lavi et al. 1996). Neglecting the thyristors voltage drops, the average counter EMF, $V_{i}$ of the inverter equals to

$$
V_{i}=\frac{3 \sqrt{6}}{\pi} \cdot \frac{V}{m} \cos \alpha
$$

and converter voltage, $V_{r}$ equals to

$$
V_{r}=\frac{3 \sqrt{6}}{\pi} \cdot \frac{s V}{n}
$$

Where, $V$ is the line-to-line source voltage, $\alpha$ is the firing angle of the inverter, $m$ is the source to converter side turn-ratio of the recovery transformer, $n$ is the stator to rotor turns ratio of the motor and $s$ is the motor slip. Since in steady state $V_{r}$ and $V_{i}$ must balance, therefore

$$
s=\frac{n}{m}|\cos \alpha|
$$

So, speed of the rotor can be controlled by varying inverter firing angle $\alpha$. The inverter recovers the slip power from the rotor when $\pi / 2<\alpha<\pi$ and can deliver energy to the rotor when $\alpha<\pi / 2$.

The power equation for each rotor phase gives

$$
\begin{aligned}
E_{2 f} I_{2 f}=\left[R_{2} I_{2}{ }^{2}+\frac{1}{3} R_{d} I_{d}{ }^{2}\right]- & \\
& {\left[\frac{1}{3}\left(1.35 \frac{V}{m} \cos \alpha-V_{\text {pec }}\right) \times I_{d}+P_{\text {mech }}\right] }
\end{aligned}
$$

Here, $I_{d}$ is the average dc current through filter inductor, $R_{d}$ is the effective resistance of filter inductor and $V_{p e c}$ is the voltage drop in the power electronics components. The total mechanical torque produced by the rotor is the sum of torque produced by the fundamental component of rotor current plus the torque produced by the rotor harmonic currents. Assuming that the torque is produced by the fundamental component of rotor current $\mathrm{I}_{2 f}$ only (Lavi et al., 1996), the rotor mechanical power is given by

$$
\begin{aligned}
P_{\text {mech }}= & {\left[\left(R_{2}+0.5 R_{d}\right) I_{2 f}{ }^{2} \frac{1-s}{s}\right]-} \\
& {\left[\left(1.35 \frac{V}{m} \cos \alpha-V_{p e c}\right) \frac{I_{d}}{3} \frac{1-s}{s}\right] }
\end{aligned}
$$

Where, $0.5 R_{d}$ is the filter inductor resistance referred to rotor side.

Slip power (power feedback), $s P_{g}$ is given by 


$$
\begin{aligned}
& s P_{g}=V_{i} I_{d} \\
& =1.35 \frac{\mathrm{V}}{\mathrm{m}} \cos \alpha I_{d}
\end{aligned}
$$

and

$$
\begin{aligned}
& P_{\text {mech }}=(1-s) P_{g}=T_{e} \omega_{r} \\
& =T_{e} \omega_{S}(1-s) \frac{2}{P}
\end{aligned}
$$

The rotor electromagnetic torque is given by,

$$
T e=\left(\frac{P}{2}\right) \frac{P_{g}}{\omega_{S}}
$$

From equations (3), (6), (7) and (8), the torque is calculated as:

$$
T e=\left(\frac{P}{2}\right) \frac{1.35 V}{\omega_{S} n} I_{d}
$$

Hence, torque is proportional to inductor current $I_{d}$. This current depends upon the difference between $V_{r}$ and $V_{i}$. So, for a fixed value of $\alpha$, the torque-slip characteristics of the drive is almost linear and resembles to the separately excited dc motor. The power flow diagram of the SPRD has been shown in Figure 2.

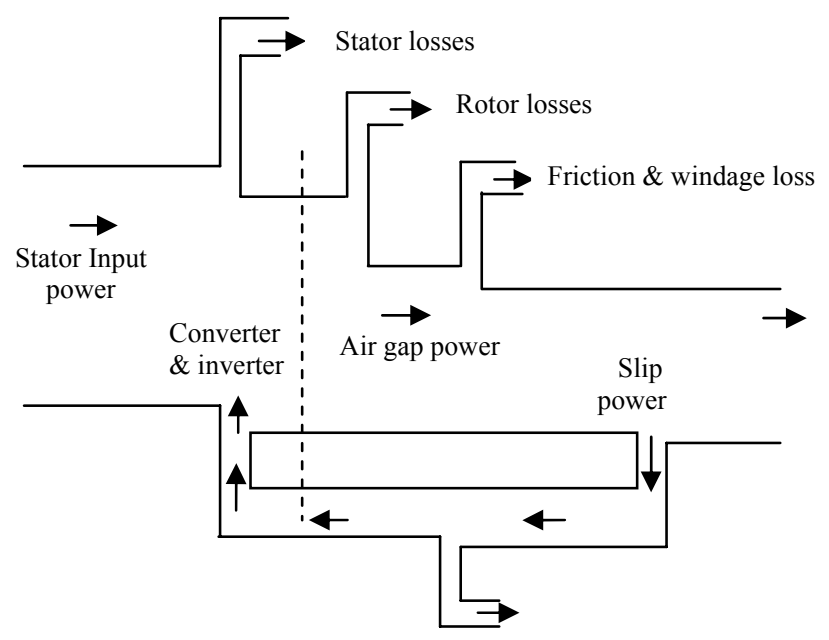

Figure 2. Power flow diagram of SPRD

\section{Simulation of the Scheme}

To study the performance of the drive, a simulation block-set in Matlab/Simulink has been implemented as shown in Figure 3. A $2 \mathrm{hp}, 400 \mathrm{~V}, 50 \mathrm{~Hz}$ wound rotor induction motor has been used for the simulation. Provision has been made to measure stator current, speed and torque of the motor. The active and reactive power input of the motor, the recovery transformer and the source have been measured using P-Q block. Provision has also been made to measure different voltages and currents of the scheme wherever required. The data has been saved to the workspace for further analysis. The other parameters of the model have been given in Appendix-A. 


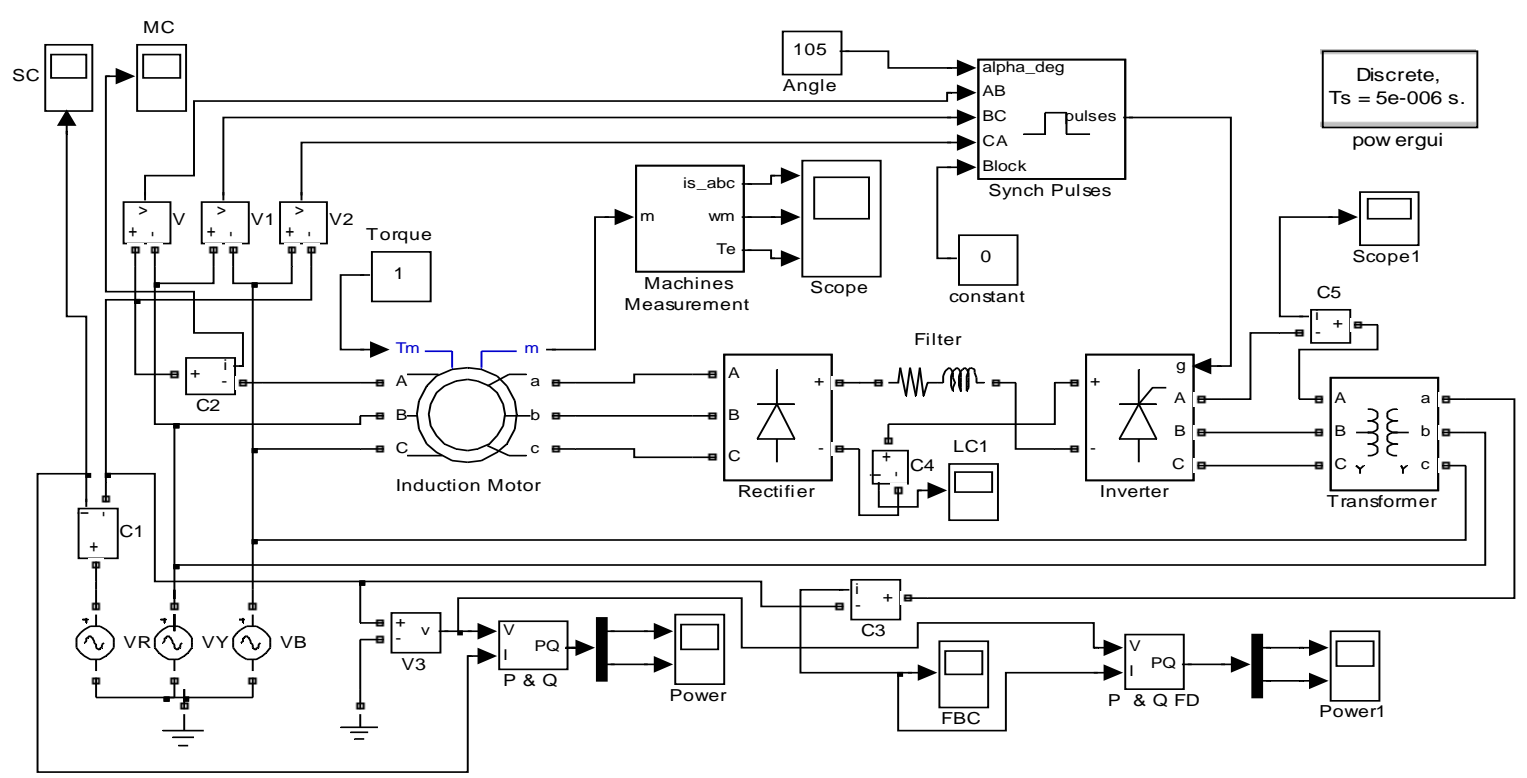

Figure 3. Simulation model of SPRD in Simulink

\section{Experimental Set-up}

For developing the experimental set-up, diodes 40USR16 have been used for the converter circuit. The diodes have been connected in three-phase full-wave bridge configuration as shown in Figure 1. A filter inductor of $25 \mathrm{mH}$ has been connected between converter and inverter circuit. For line commutated inverter power circuit, six SCR TYN612 connected in three-phase full wave bridge configuration have been used.

The experimental set-up of the firing circuit of the drive is microcontroller based. The configuration of the firing pulse generator scheme is shown in Figure 4. Three number of single-phase; star-star connected step-down transformers have been used to get synchronized reference signals from the supply. The signal available from each step-down transformer has been fed to a high gain operational amplifier LM324 consisting of four-independent internal channels. The zero crossing of each phase is detected here and the rectangle output signals from LM324 are fed to the microcontroller unit.

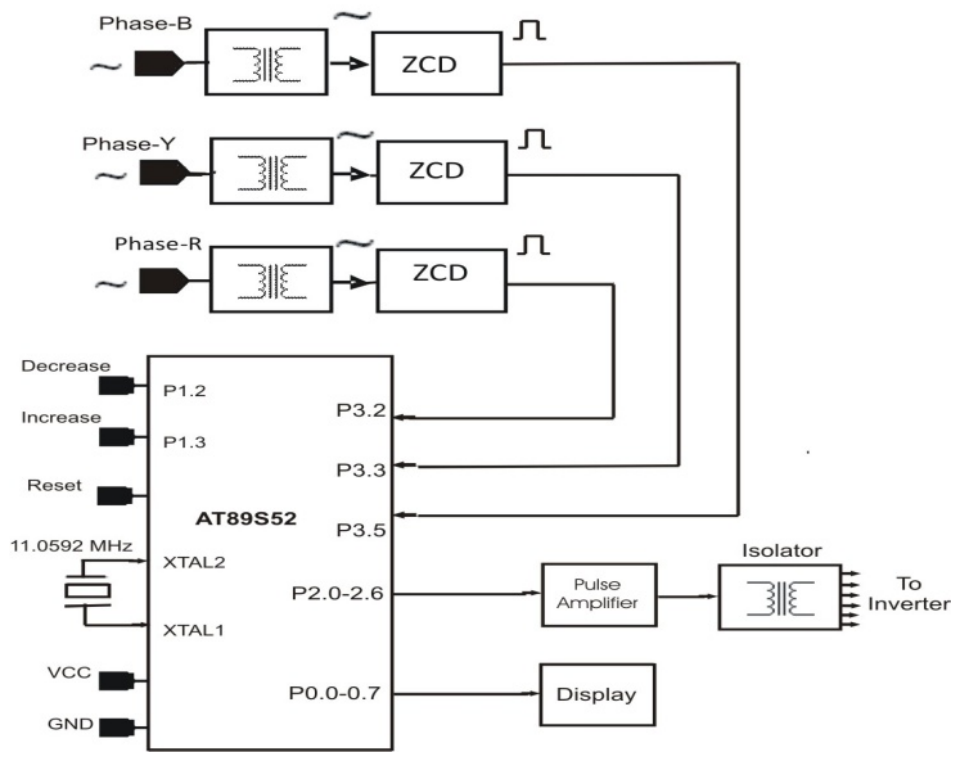

Figure 4. Block diagram of micro-controller based firing pulse generator 
Microcontroller ATMEL AT89S52 has been used to produce firing pulses which is a low power, high performance 40 pin CMOS 8-bit microcontroller. Program code has been developed to get the required output in the form of synchronized firing pulses from the microcontroller. The firing pulses obtained from the port P2.0-2.6 have been amplified and shaped properly using driver circuits for proper firing of the thyristors. The pulse transformers have been used to separate the high voltage cathode and low voltage gate circuits of the thyristors. The gate pulse width has been reduced to $100 \mu$ s to avoid the saturation of pulse transformer. An LCD display unit has been connected at port P0.0-0.7 to see the present firing angle. An 11.0592 MHz external crystal oscillator has been used as input to the internal clock operating circuit of the microcontroller. Provision has been made to increase or decrease the firing angle at port P1.3 and P1.2 respectively. Reset has also been provided to refresh the system memory. A high signal on this pin for two machine cycles while the oscillator is running resets the microcontroller. Regulated $5 \mathrm{~V}$ power supply has been given to microcontroller, display and pulse amplifier circuits.

\section{Simulation Results}

Simulation results show that by varying firing angle (above 90 degree) in small intervals, motor speed can be controlled from zero to nominal speed. The motor speed vs. time characteristics at two different firing angles have been shown in Figure 5. It can be observed that steady state speed for higher firing angle is less as compared to lower firing angle. The upper value of firing angle is restricted to $165^{\circ}$ for the safe commutation of thyristors (Bose, et al. 1998, Dubey et al. 2008).

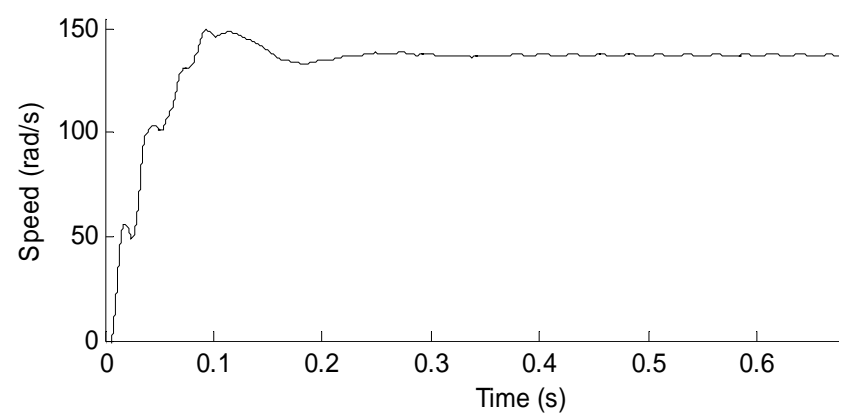

(a)

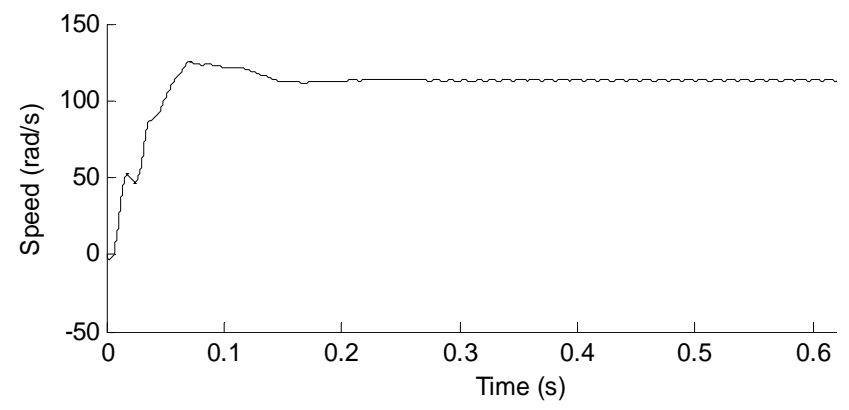

(b)

Figure 5. Motor speed at (a) 92 degree (b) 100 degree firing angle

Moreover, inverter circuit consumes negative active power and positive reactive power from line side as shown in Figure 6. This means that active power is returned to the network but a large amount of reactive power is absorbed from the source. Because of the reactive power consumption, the overall power factor of the scheme becomes low. 


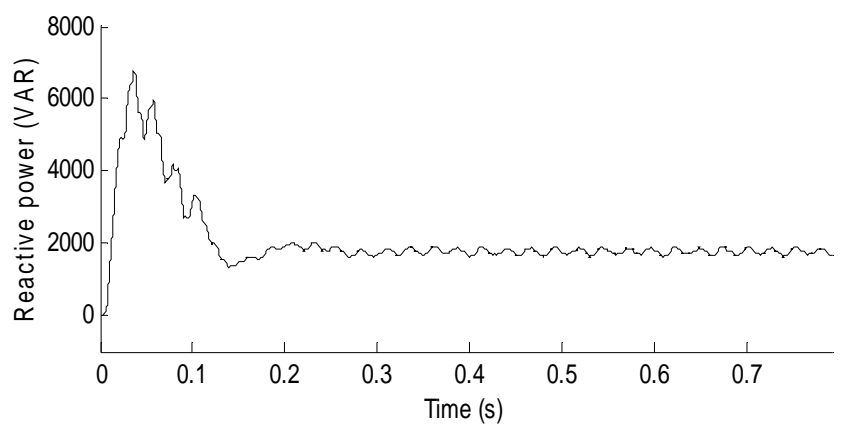

(a)

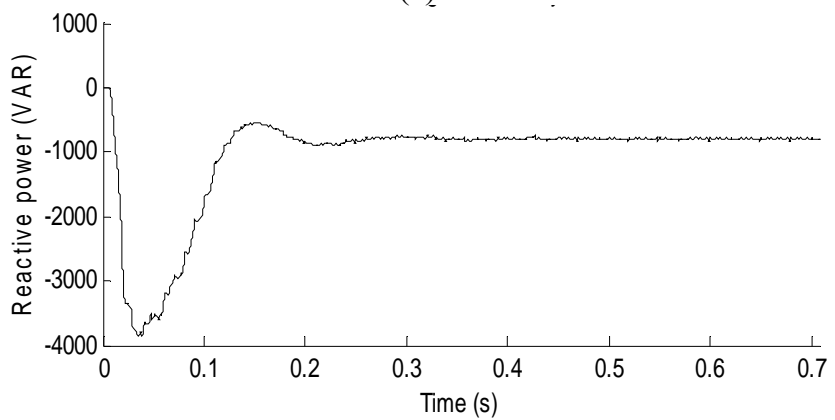

(b)

Figure 6. Reactive power drawn by (a) Motor (b) Inverter

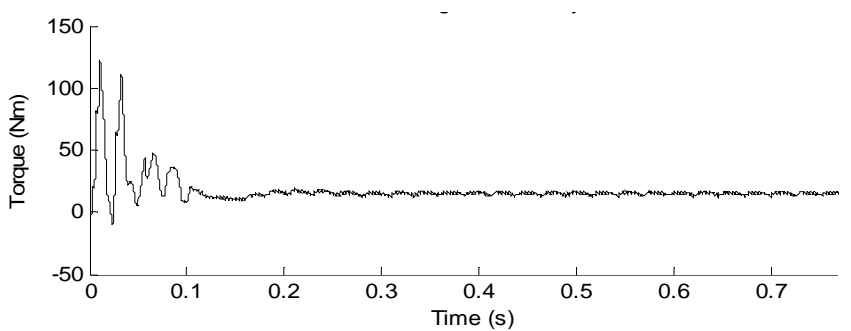

(a)

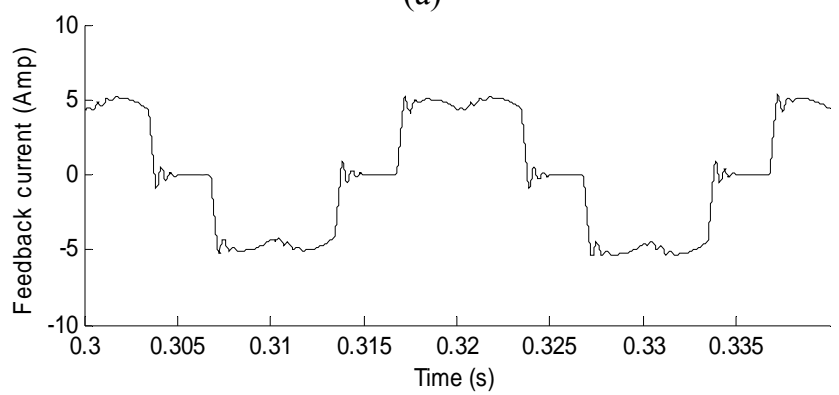

(b)

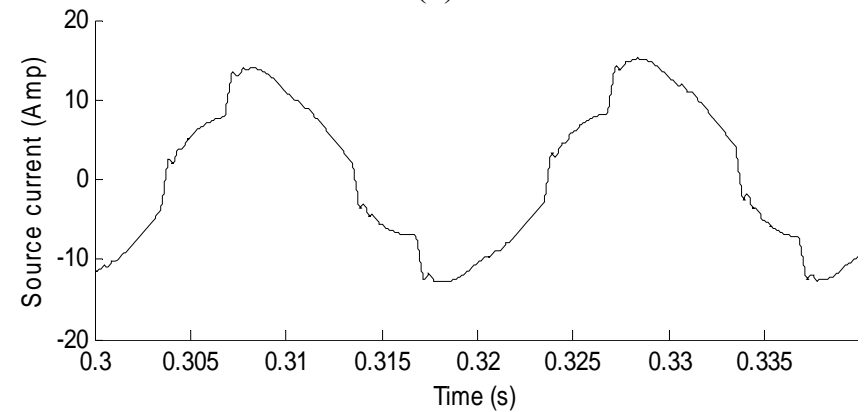

(c)

Figure 7. (a) Motor torque (b) Feedback current (c) Source current 
The presence of power electronic converter and inverter circuit in this system, also cause low frequency odd harmonics $\left(3^{\text {rd }}, 5^{\text {th }}\right.$, $7^{\text {th }} \ldots$ ) injection to the network. Motor torque, feedback current and source current vs. time characteristics have been shown in Figure 7. It can be observed that, the feedback current waveform and the source current waveform are distorted. This leads to increased torque ripple and consequently motor temperature is increased. Instead of sine wave, the feedback current (recovery transformer current) is almost a rectangular wave. The THD of the source current has been found to be $11.57 \%$.

The non-sinusoidal motor current and inverter feed-back current affect line-side current and inject harmonics in the network. Fast Fourier Transform (FFT) window of source current wave form has been shown in Figure 8 . It can be observed that it consists of sub-harmonic corresponding to $25 \mathrm{~Hz}$ and multiple harmonics corresponding to third, fifth and seventh harmonics. It can be further observed that, fifth and seventh harmonics are the dominant harmonics.

Fundamental $(50 \mathrm{~Hz})=12.98, \mathrm{THD}=11.57 \%$

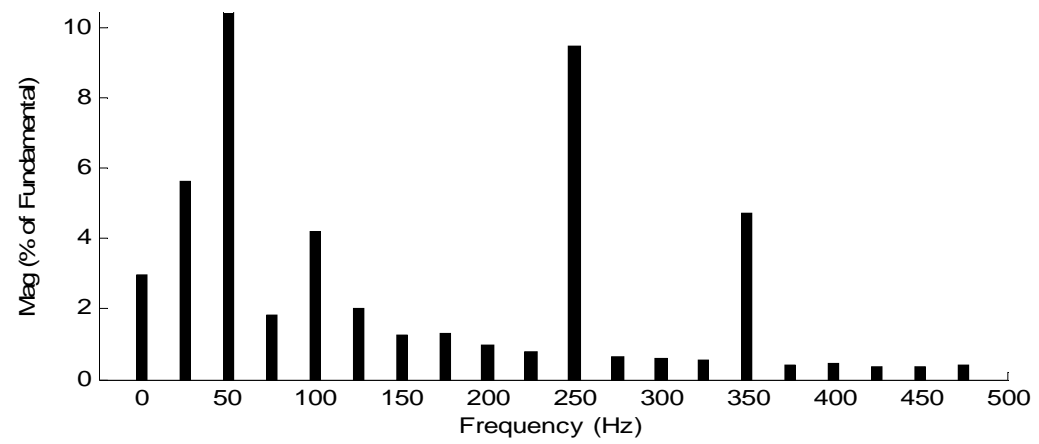

Figure 8. FFT window of source current

\section{Experimental Results}

The performance characteristics of the drive have also been analyzed using the experimental set-up. The variation of the rotor speed at constant load and variable firing angle has been shown in Figure 9 (a). Similarly, variation of the rotor speed with respect to loop current (inductor current) has been plotted in Figure 9(b).



(a)

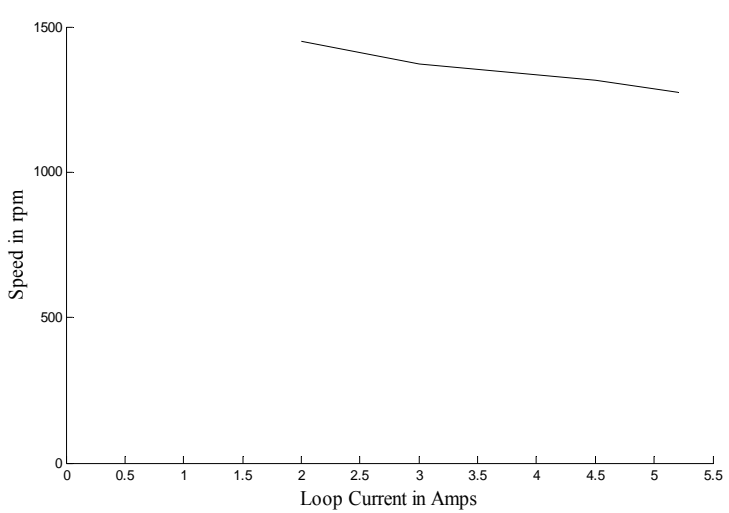

(b)

Figure 9. Variation of speed with (a) firing angle (b) loop current 
The input power of the drive with and without slip power recovery has been shown in Figure 10. If we neglect the inverter and transformer losses, we can find that for the same load, the input power taken from the source with slip power recovery scheme is less than that of power consumed without slip power recovery scheme. Hence an increase in efficiency of the drive can be obtained.

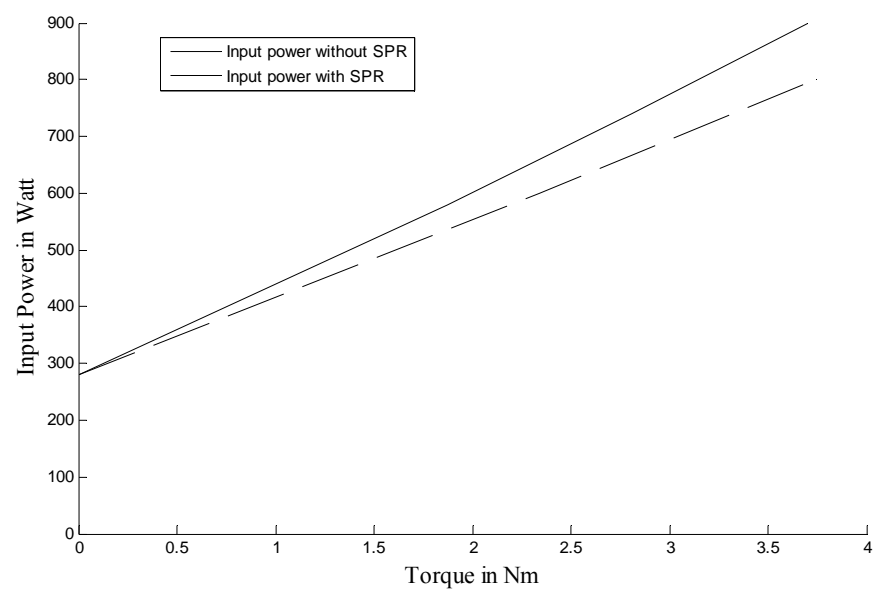

Figure 10. Variation of input power with load

Figure 11 shows the efficiency of the drive with external rotor resistance speed control and slip power recovery control method. The results show that the efficiency of slip power recovery control drive is $3.66 \%$ higher than that of rotor resistance control method.

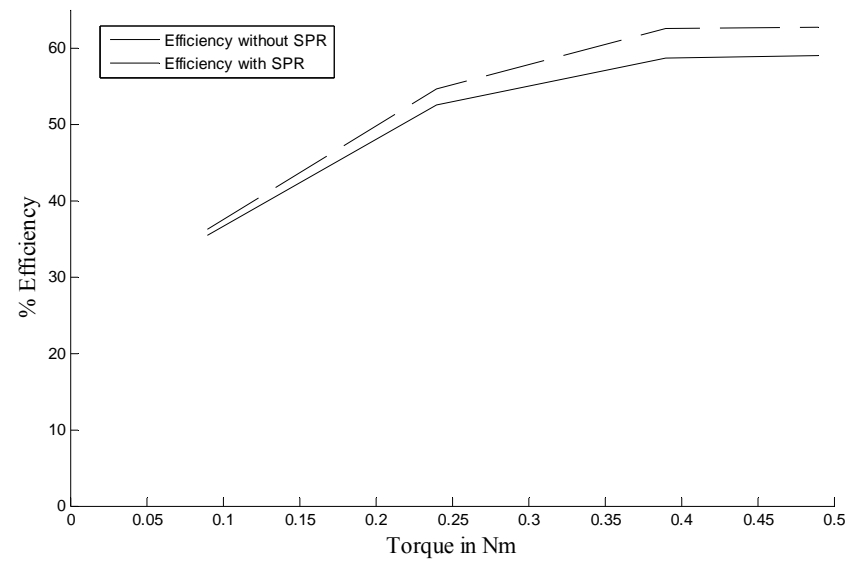

Figure 11. Comparison of drive efficiency

Figure 12 shows that for a fixed firing angle, the slip power recovered from the rotor circuit increases with increase in load torque (resulting in reduced speed of the drive). 


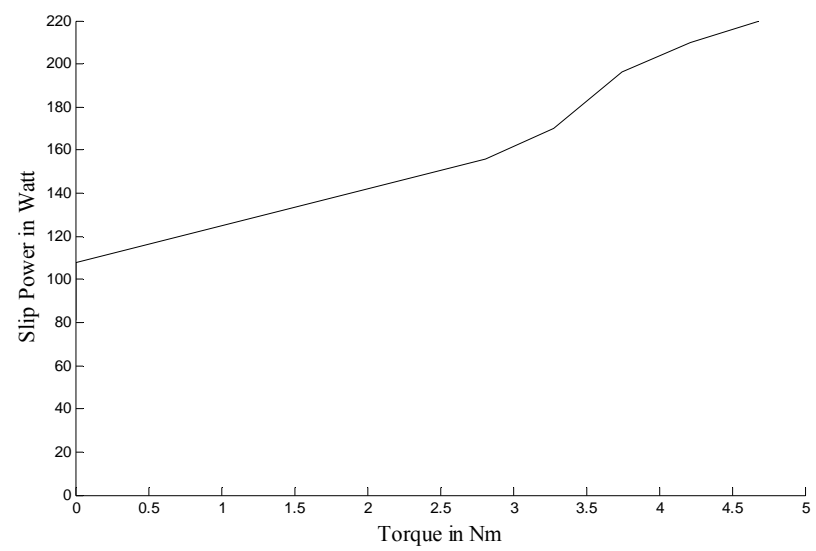

Figure 12. Variation of slip power with load torque.

Figure 13 shows the variation of load torque with respect to de link inductor current (loop current). It is observed that the torque of the drive varies linearly with the de link inductor current. This exhibits that the drive has similar characteristics as that of separately excited dc motor in which torque varies linearly with the armature current.

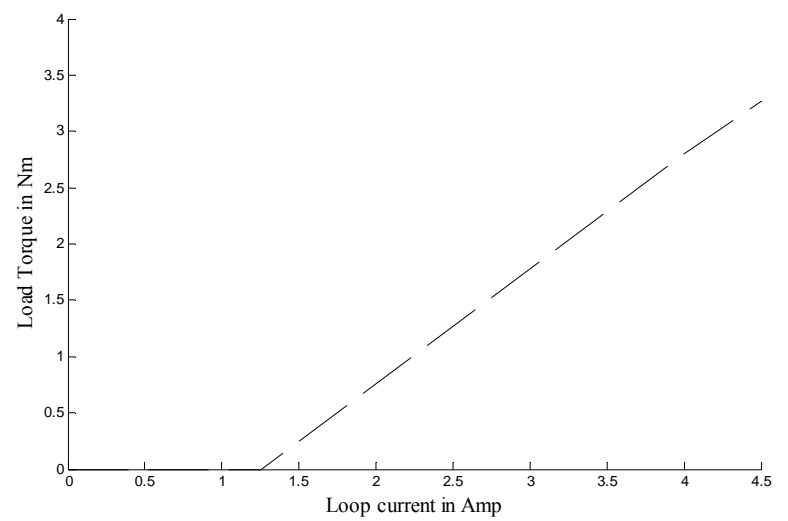

Figure 13. Load torque vs. loop current (inductor current)

The reactive power absorbs by the motor and the line commutated inverter makes the overall power factor of the drive very low. This fact is evident in Figure 14, where the variation of input power factor vs. load torque is plotted with/without SPRD. Here it can be seen that the power factor of the drive without SPRD is about 0.8 (lagging) at full load whereas it is about 0.4 (lagging) with slip power recovery scheme.



Figure 14. Variation of input power factor with load 


\section{Conclusions}

In this paper, the slip recovery energy method for the speed control of three-phase slip ring induction motor has been investigated. The performance equations have been drawn and a simulation block-set model in Matlab/Simulink has been implemented. A microcontroller based open-loop speed control experimental set-up has also been developed in the laboratory. The following conclusions have been drawn from the study:

1. The torque of the drive varies linearly with the de link current. Hence, the drive has similar characteristics as that of separately excited dc motor.

2. The increase in efficiency has been observed as compared to rotor resistance method of speed control.

3. The simulation/experimental results show the overall reduced power factor of the drive.

4. Presence of converter and line commutated inverter results in harmonic injection on the source side.

5. Presence of current harmonics in stator and rotor windings causes additional heating of motor. Thus, de-rating of the drive is required for the same load as compared to rotor resistance control method.

\section{Nomenclature}

$\mathrm{V}_{\mathrm{i}} \quad$ Inverter voltage

$\mathrm{V}_{\mathrm{r}} \quad$ Converter voltage

$\mathrm{P}_{\text {mech }}$ mechanical power

s slip

A Firing angle

$\mathrm{T}_{\mathrm{e}} \quad$ Electromagnetic torque

$\omega_{\mathrm{s}} \quad$ synchronous angular speed

$\mathrm{P} \quad$ No. of poles

$\mathrm{R}_{\mathrm{d}} \quad$ Effective resistance

$\mathrm{R}_{r} \quad$ Rotor resistance

$\mathrm{R}_{s} \quad$ Stator resistance

$\mathrm{L}_{\mathrm{r}} \quad$ Rotor leakage reactance

$\mathrm{L}_{\mathrm{s}} \quad$ Stator leakage reactance

$\mathrm{a}_{\mathrm{T}} \quad$ turn ratio of the transformer

\section{Appendix}

Slip ring induction motor: 3-phase, $2 \mathrm{hp}, 400$ volt, $4.5 \mathrm{amps}, 50 \mathrm{~Hz}, 1440 \mathrm{rpm}, \mathrm{Y}-\mathrm{Y}$ connected.

Parameters: Stator resistance $=4.8 \Omega$; Rotor resistance $=4.2 \Omega$; Stator leakage reactance $=9.5 \Omega$; Rotor leakage reactance $=9.5$ $\Omega$; Magnetizing reactance $=185 \Omega$; Stator to rotor turn ratio $=5$.

Other Parameters of the drive system: Turns ratio of recovery transformer (inverter to line side) $=0.2$; Resistance of smoothing inductor $=2 \Omega$; Inductance of smoothing inductor $=0.025 \mathrm{H}$

\section{Acknowledgement}

Authors acknowledge Department of Electrical Engineering, Mullana University, Mullana for providing necessary support to procure hardware for implementation of the work.

\section{References}

Leonharn, W., 1985, .Control of Electric Drives., Springer Verlag, Berlin.

Krishnan, R., 2001, .Electric Motor Drives, Modeling and Analysis. Prentice Hall, Inc.

Stiebler, M., 2010 .Doubly-fed asynchronous machine for low voltage drives. Electrical Machines (ICEM), 2010 XIX International Conference on Electrical Machines, Vol. 1, No. 6, pp.6-8.

B.A.T. Al Zahawi and B.L. Jone s, Rotor Rectifier on Motor Performance in Recovery Drives," Canadian Electrical Journal, Vol 12, No 1, 1987, pp 24-32.

J.E. Brown, W. Drury, B.L. Jones and P. Vas, "Analysis of the Periodic Transient State of a Static Kramer Drive," Proc lEE, Vol 133, Pt.B, No I, Jan 1986, pp 21-30.

S.R. Doradla, S. Chakravorty and K.E. Hole, "A New Slip Power Recovery Scheme with Improved Supply Power Factor., IEEE Trans on Power Electronics, Vol 3, No 2, April 1988, pp 200-207.

Krause,P. C., Wasynczuk, O., Hildebrandt,M. S., .Reference Frame Analysis of a Slip Energy Recovery System. IEEE Trans on Conversion., Vol 3, No.2, June 1988, pp 404-408. 
Akpinar, P. and Pillay P., 1990, .Modeling and performance of slip energy recovery induction motor drive. IEEE Trans. on Energy Conversion, Vol. 5, No. 1, pp. 203-210.

Fan, L., Ji, Sheng, Lipo, T. A., 1990, .A new energy recovery scheme for doubly fed variable speed induction motor drives. Wisconsin Electrical Machine and Power Electronics Consortium, Research Report 90-3.

Papathanasiou S. A., Papadoupolous M. P., 1998, .Commutation angle analysis of slip energy recovery drive. IEEE Trans. on Energy Conversion, Vol. 13, No. 1, pp. 21-26.

Refoufi L. and Pillay, P., 1994, .Harmonic analysis of slip energy recovery induction motor drive. IEEE Trans. on Energy Conversion, Vol. 9, No. 4, pp. 665-671.

Faiz, J., Barati, H., and Akpinar, E., 2001, . Harmonic analysis and performance improvement of slip energy recovery induction motor drive. IEEE Trans. on Power Electronics, Vol. 16, No. 3, pp. 410-417.

Tunyasrirut S.,et al., 2008, .DSP based modified slip energy recovery drive using a 12-pulse converter and shunt chopper for speed control system of a wound rotor induction motor. Electric Power System Research, Vol. 78, No. 6, 861-872.

Lavi, A. and Polge, R.J., 1966, .Induction motor speed control with static inverter in the rotor. IEEE Trans. on power apparatus and systems, Vol. PAS- 85, No.1, pp.76-84.

Dick, B., 2009, .Wound Rotor Slip Power Recovery Drive Experience and Applications. Cement Industry Technical Conference Record, 2009 IEEE, Vol. 1, No.1, pp.1-4.

Bose, B. K., 1988, .Power Electronics and AC Drive. Englewood Cliffs, NJ: Prentice-Hall.

Dubey, G.K., 2008.Power semiconductor controlled drives., PHI. Edition.

Biographical notes

Ajay Kumar is with the Department of Electrical Engineering, University of Emerging Science and Technoloy, Baddi, H. P. His research interests include power system operation, drives.

Sanjeev Aggarwal is a Associate Professor in the Department of Electrical Engineering, Mullana University, Mullana, India. He graduated from DCRUST, Murthal, did his masters in Power Systems from NIT Kurukshetra, and Ph,D. from NIT Kurukshetra in 2009. His research interest include power systems operation in new environment, price forecasting, neural networks, and wind energy systems. He is a life member of ISTE.

L. M. Saini received his B. tech. from GNDEC, Ludhiana in 1987, M. Tech. from KUK, University, and ph.D. from KUK university in 2002 . He is presently associate prof. in the Dept. of Electrical Engineering, at NIT Kurukshetra. His research interests include neural networks, image processing, wavelets, signal processing, price forecasting, load forecasting, and microcontrollers. He is a life member ISTE (India).

A. Kumar received B. Tech. in electrical engineering from G. B. Pant University of Agri. and Technology, Pant nagar in 1988, M. E. in Power Systems from Punjab University, Chandigarh in 1994 in honors and Ph.D. from Indian Institute of Technology Kanpur, India in 2003, respectively. He is an Assoc. Professor in the Department of Electrical Engineering, National Institute of Technology Kurukshetra, India. His research interests include power system restructuring, power system dynamics, renewable energy, demand side management, and distributed generation. He is a life member of IE (India), ISTE (India), and member of IEEE/IEEE PES.

Received December 2010

Accepted March 2011

Final acceptance in revised form April 2011 